\title{
CIRCULAR ECONOMY AND DIGITAL TECHNOLOGIES: A REVIEW OF THE CURRENT RESEARCH STREAMS
}

\author{
Trevisan, Adriana Hofmann (1); \\ Zacharias, Isabela Simões (1); \\ Liu, Qinglan (2); \\ Yang, Miying (2); \\ Mascarenhas, Janaina (1)
}

1: São Carlos School of Engineering, University of São Paulo, Department of Production Engineering, São Carlos, Brazil;

2: College of Engineering, Mathematics and Physical Science, University of Exeter, Exeter, UK

\begin{abstract}
The interest in the Circular Economy (CE) has grown in recent years. Digital technologies (DTs) have demonstrated a potential synergy to achieve circular goals at the micro, meso, and macro-level. Although several studies in literature explore DTs and CE linkage, they have not been identified according to their primary research themes. This paper aims to identify the main research streams addressing CE and DTs. From a Systematic Literature Review and Content Analysis, we reviewed 40 articles and classified three primary research streams. (1) Industry 4.0 (I4.0) focuses on the relevance and role of I4.0 in the transition to a CE. (2) The Business research stream evaluated the connection between digital transformation and business. (3) The Sustainability research stream discusses sustainability issues such as waste management and smart cities. Based on the analyzed studies' purposes and gaps, we provide a research agenda for further research. Additionally, we explain the implications of DTs and CE to research on engineering design. Our paper guides researchers in their future research to focus on gaps that have not been answered and position their studies according to their research streams.
\end{abstract}

Keywords: Circular economy, Sustainability, Industry 4.0, Business models and considerations

\author{
Contact: \\ Mascarenhas, Janaina \\ University of São Paulo \\ Department of Production Engineering \\ Brazil \\ jana.mascarenhas@usp.br
}

Cite this article: Trevisan, A. H., Zacharias, I. S., Liu, Q., Yang, M., Mascarenhas, J. (2021) 'Circular Economy and Digital Technologies: A Review of the Current Research Streams', in Proceedings of the International Conference on Engineering Design (ICED21), Gothenburg, Sweden, 16-20 August 2021. DOI:10.1017/pds.2021.62 


\section{INTRODUCTION}

The Circular Economy (CE) concept has gained the attention of academics, businesses, and governments in recent years (Geissdoerfer et al., 2017; Ellen MacArthur Foundation, 2019). CE is an umbrella concept that implies "a regenerative system in which resources input and waste, emission, and energy leakage are minimized by slowing, closing, and narrowing material and energy loops" (Geissdoerfer et al., 2017). It opposes a linear model of consumption and defends a resource-oriented approach (Sauvé, Bernard and Sloan, 2016) in which creating value is decoupled from raw-material extraction (Ellen MacArthur Foundation, 2015, 2019) by slowing and closing loops (Bocken et al., 2016). This idea is extended both to biological cycles (e.g., anaerobic digestion, farming) and technical cycles (e.g., remanufacturing, recycling) in distinct levels of application, i.e., micro, meso, and macro-level (Ghisellini, Cialani and Ulgiati, 2016).

Digital technologies (DTs) have shown promising applications to advance the transition to a CE (Pagoropoulos, Pigosso and McAloone, 2017) at all levels. In the micro-level, which is restricted to a single company (Ghisellini, Cialani and Ulgiati, 2016), CE has been associated with business model innovation (Pieroni, McAloone and Pigosso, 2019). DTs are employed to reach and leverage circular goals through connected capabilities such as monitoring, controlling, optimization, and automation (Porter and Heppelmann, 2014; Nasiri, Tura and Ojanen, 2017; Ingemarsdotter et al., 2019). For example, IoT allows companies to track products throughout their lifecycle, which contributes to promoting R's strategies (e.g., reuse, remanufacturing, and recycling) (Ingemarsdotter et al., 2019) and product sharing (Guzzo et al., 2019).

Industrial symbiosis, which is an example of meso-level application, has helped companies through CE to improve their environmental performance (Ghisellini, Cialani and Ulgiati, 2016). CE has been previously associated with possibilities of enhancing resource efficiency and productivity (Kristoffersen et al., 2020). Song et al. (2017) described a case in which Big Data was applied to map potential synergies between companies allocated in a specific area to promote industrial symbiosis strategy.

In the macro-level application, which corresponds to large areas such as cities (Ghisellini, Cialani and Ulgiati, 2016), DTs were employed to drive sustainable development. For example, Esmaeilian et al. (2018) highlighted the use of IoT to solve waste management problems in cities. In this case, smart trash bins can be developed considering a life cycle perspective, which includes beginning of life (BOL), middle of life (MOL), and end of life (EOL) phases, embracing all the stages of waste management (Esmaeilian et al., 2018).

To sum up, CE has been established as a fundamental concept to achieve environmental and financial benefits. DTs plays a crucial role in the transition to a CE (Pagoropoulos, Pigosso and McAloone, 2017). Several studies in the literature explore DTs and CE linkage and stress their synergic potential (Nobre and Tavares, 2017; Chauhan, Sharma and Singh, 2019; Pham et al., 2019). However, until now, the main research streams of these studies are still unclear. From the theoretical perspective, research streams provide an overview of the field and offer an understanding of the differences among the studies and how research has been advancing. Based on that, our research question is What are the main research streams that associate circular economy and digital technologies?

This paper aims to identify the main research streams in studies addressing CE and DTs. We provided an overview of the studies presented in literature, and summarized the research methods, key concepts, relevant journals, and principal research aims of each stream. Additionally, a research agenda is offered with the gaps expressed in the analyzed studies. To literature, our paper can be used by researchers as a guide to their future studies.

\section{METHODOLOGY}

To identify the research themes that integrate CE and DT concepts and provide an overview of previously published studies, we apply a Systematic Literature Review (SLR) approach outlined by Tranfield, Denyer and Smart (2003). The SLR process allows a wide range of articles to be selected and analyzed in order to find evidence about a particular field of research (Webster and Watson, 2002; Tranfield, Denyer and Smart, 2003). Systematic literature review is an appropriate method to identify theoretical and empirical findings, key constructs, and to highlight opportunities for future studies that are still unexplored (Webster and Watson, 2002; Paul and Criado, 2020). This method supports knowledge creation through an organized and rigorous scientific procedure (Tranfield, Denyer and Smart, 2003). 
As suggested by Paul and Criado (2020), we chose well-established bibliographic databases, which cover the important articles published under our theme of study. The selected databases were Scopus, Web of Science, EBSCOhost, ProQuest, and ScienceDirect. The searches were conducted in February 2020, and only English language articles published in peer-reviewed journals and at conferences were analyzed. The keywords adopted were "Circular Economy" and "Circularity" in combination with "digit*", "Internet of Things", "IoT", "Big data", "Artificial Intelligence", "AI", and "Industry 4.0". The word "digit*" was applied to select documents containing variance in terms of digitization, digitalization, digital intelligence, and others. DTs like IoT, Big Data, and AI were chosen because previous literature argue the promising potential of these technologies for a CE (Bressanelli et al., 2018a; Ellen MacArthur Foundation, 2019). Table 1 presents the research protocol and the criteria for including and excluding documents.

Table 1. Research protocol and selection criteria

\begin{tabular}{|l|c|}
\hline Research Protocol & Description \\
\hline Databases & Scopus, Web of Science, Science Direct, EBSCO and ProQuest \\
\hline Search string & $\begin{array}{c}\text { TITLE-ABS-KEY ("Digit*” OR “Internet of Things" OR "IoT" OR } \\
\text { "Big data" OR "Artificial intelligence" OR “AI" OR "Industry 4.0") } \\
\text { AND ("Circular economy" OR "Circularity"). }\end{array}$ \\
\hline Language & English-only \\
\hline Data range & Until February 2020 \\
\hline Publication type & Peer-reviewed journals and conference papers \\
\hline Research method & All included \\
\hline Inclusion criteria & $\begin{array}{c}\text { Papers addressing both circular economy and digital technologies } \\
\text { fields; } \\
\text { Papers addressing biological or technical cycle }\end{array}$ \\
\hline Exclusion criteria & $\begin{array}{c}\text { Technical articles focusing on algorithms, optimization, simulation, } \\
\text { and modelling. }\end{array}$ \\
\hline
\end{tabular}

In total, 877 articles were returned after deleting duplicates. After applying the inclusion and exclusion criteria mentioned above, 40 articles were selected and deeply reviewed. Then, we carried out a content analysis based on Elo and Kyngäs (2008) guidelines. The Maxqda ${ }^{\circledR}$ and Nvivo ${ }^{\circledR}$ software were used for coding, categorization, and data analysis. Two researchers conducted the entire process simultaneously to minimize bias. In order to identify the main research streams regarding DT and CE integration, we analysed four dimensions, namely the purpose of the study, method adopted, main results, and future research opportunities. Through the analysis of each dimension, we identify emerging patterns, shared characteristics, similarities among the codes and categorize them. For example, the concept of digitalization has been explored in articles that focus on circular business models. Thus, digitization corresponds to a key concept of the business research stream. In the next following sections, each stream is discussed in more detail.

\section{RESULTS AND DISCUSSION}

The three research streams that emerged through our analysis were Industry 4.0 (I4.0), Business and Sustainability. Table 2 shows an overview of each identified research stream. The studies were classified according to their key concepts, analytical methods, principal journals, study purposes, and gaps that still need to be addressed by the literature. Each research stream contains characteristics that both distinguish it from the others and stress overlapping concepts. 
Table 2. Main elements of each identified research streams

\begin{tabular}{|c|c|c|c|}
\hline $\begin{array}{l}\text { Research } \\
\text { Streams }\end{array}$ & RS1: Industry 4.0 & RS 2: Business & RS 3: Sustainability \\
\hline $\begin{array}{l}\text { Key } \\
\text { concepts }\end{array}$ & $\begin{array}{l}\text { Remanufacturing; Reverse } \\
\text { supply chain management; } \\
\text { Smart circular economy; DT } \\
\text { capabilities; Sustainable } \\
\text { operations management; } \\
\text { Development of SmartTags }\end{array}$ & $\begin{array}{l}\text { Digitalization; Smart PSS; } \\
\text { Circular business model; } \\
\text { Supply chain management; } \\
\text { Stakeholder perspective; } \\
\text { Circular strategies; Sharing } \\
\text { Economy }\end{array}$ & $\begin{array}{r}\text { Supply chain } \\
\text { management; Waste } \\
\text { management; } \\
\text { Agricultural waste; } \\
\text { Industrial symbiosis; } \\
\text { Smart cities }\end{array}$ \\
\hline $\begin{array}{l}\text { Analytical } \\
\text { Methodolo } \\
\text { gy }\end{array}$ & $\begin{array}{c}\text { (Systematic) Literature Review; } \\
\text { Case study; Workshops; } \\
\text { Interpretive Structural Modeling } \\
\text { (ISM); others }\end{array}$ & $\begin{array}{c}\text { (Systematic) Literature } \\
\text { Review; Case study; } \\
\text { Interviews; Workshops; } \\
\text { ISM; others }\end{array}$ & $\begin{array}{r}\text { (Systematic) } \\
\text { Literature Review; } \\
\text { Case study; LCA } \\
\text { Interviews; Workshop }\end{array}$ \\
\hline $\begin{array}{l}\text { Main } \\
\text { journals }\end{array}$ & Diverse & $\begin{array}{c}\text { Sustainability; Journal of } \\
\text { Cleaner Production; } \\
\text { Technological forecasting } \\
\text { and social change; Procedia } \\
\text { CIRP } \\
\end{array}$ & $\begin{array}{r}\text { Resource } \\
\text { Conservation and } \\
\text { Recycling; Journal of } \\
\text { Cleaner Production }\end{array}$ \\
\hline Purpose & $\begin{array}{c}\text { Exploring the link between I4.0 } \\
\text { and CE (4)*; The role of I4.0 } \\
\text { technologies in a CE (4); } \\
\text { Application of IoT and other } \\
\text { technologies (1) in } \\
\text { Remanufacturing (2), Reverse } \\
\text { Logistic (1), Metallurgy } \\
\text { processes (1), Reverse Supply } \\
\text { Chain (1), and waste } \\
\text { management (1). }\end{array}$ & $\begin{array}{l}\text { Transition to CE through } \\
\text { DTs (5); Understanding of } \\
\text { the main opportunities and } \\
\text { challenges of DTs to the CE } \\
\text { (3); DTs enabling PSS BM } \\
\text { (3); DTs enabling CBM (2); } \\
\text { The role of big data to } \\
\text { management and sustainable } \\
\text { business practices (2); } \\
\text { Application of IoT for } \\
\text { circular strategies (2) }\end{array}$ & $\begin{array}{r}\text { DTs to improve } \\
\text { efficiency and } \\
\text { utilization of resources } \\
\text { (3); Barriers and } \\
\text { opportunities to smart } \\
\text { waste management } \\
\text { (2); Application of big } \\
\text { data in industrial } \\
\text { symbioses (1) and } \\
\text { agriculture (1); } \\
\text { Blockchain and other } \\
\text { Application of DTs for } \\
\text { achieving operational } \\
\text { excellence (1) }\end{array}$ \\
\hline $\begin{array}{l}\text { Research } \\
\text { Gaps }\end{array}$ & $\begin{array}{l}\text { Economic viability of using DT; } \\
\text { Challenges and Barriers of I4.0; } \\
\text { Test/validate concepts, } \\
\text { frameworks, models, etc; } \\
\text { Empirical evidence of CE and } \\
\text { I4.0 application in practice; } \\
\text { Indicators and critical success } \\
\text { factors to measure gains; } \\
\text { Support of DT to bioeconomy } \\
\text { and waste recovery; } \\
\text { Required capabilities to CE- } \\
\text { I4.0; } \\
\text { Impact of I4.0 DT for } \\
\text { Stakeholders, CBM, and } \\
\text { consumer acceptance; } \\
\text { National policies to implement } \\
\text { CE-I4.0; } \\
\text { Application of DT in emerging } \\
\text { countries and different cultures. }\end{array}$ & \begin{tabular}{|} 
Test/validate concepts, \\
frameworks, models, etc; \\
Measure environmental \\
impacts and rebound effects; \\
Empirical evidence and \\
quantitative results; \\
Investigate the role of DT in \\
different BM and to \\
competitiveness; \\
Impact of I4.0 DT in the \\
CBM design and consumer \\
acceptance; \\
Explore DTs beyond IoT and \\
BDA for CE; \\
Tool for mapping the current \\
state of DT-CE \\
implementation; \\
Address barriers to \\
implementing DT-CE; \\
Sustainability impact of IoT.
\end{tabular} & $\begin{array}{r}\text { Test/validate } \\
\text { concepts, frameworks, } \\
\text { models, etc; } \\
\text { Empirical evidence } \\
\text { about the benefits of } \\
\text { DT for CE; } \\
\text { Challenges and } \\
\text { Barriers to } \\
\text { implementing DT } \\
\text { faced by diverse } \\
\text { countries; } \\
\text { Blockchain } \\
\text { application and other } \\
\text { DT to achieve CE; } \\
\text { More case studies } \\
\text { about smart waste } \\
\text { management. }\end{array}$ \\
\hline \# of papers & $15 / 40$ & $17 / 40$ & $8 / 40$ \\
\hline
\end{tabular}


Figure 1 presents how the three research themes interconnect to each other. This model highlights multidisciplinary knowledge areas, such as supply chain management (SCM), sharing economy, smart cities, etc. It reinforces areas of studies that need greater integration, as they are being addressed separately. For example, social issues are being debated more by sustainability scholars. Only I4.0 researchers are exploring the capabilities required for a digital transformation towards a CE. In the following sections, we go deep into these discussions and present in detail each research stream.

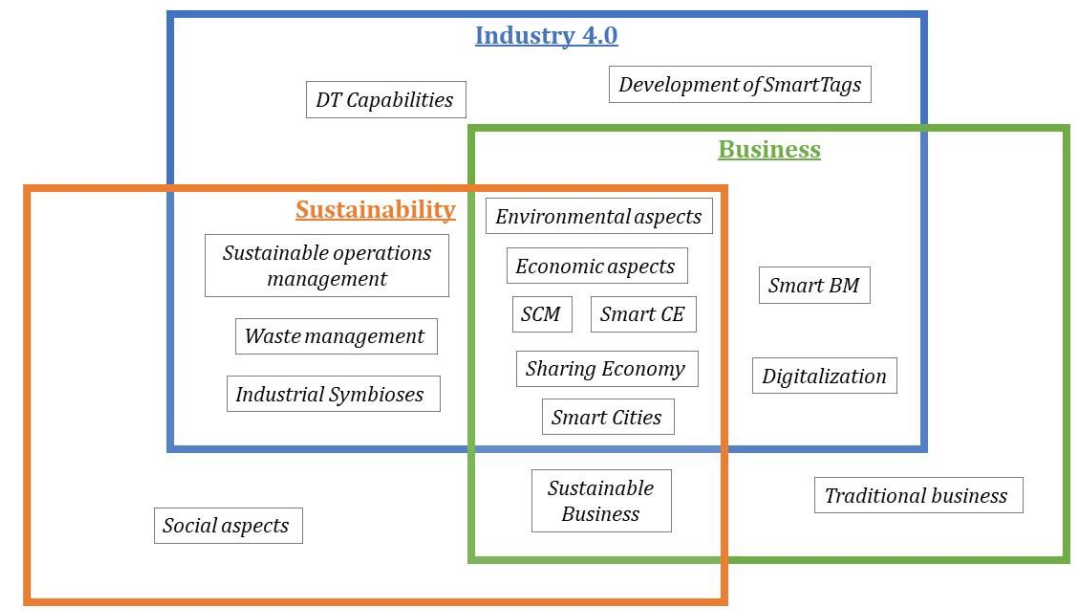

Figure 1. Intersection of the research streams

\subsection{Research Stream 1: Industry 4.0}

The first stream encompasses studies discussing the importance and the role of I4.0 in the transition to a CE. As suggested by the name of the research stream, the papers focus on the fourth industrial revolution that can be understood as a "manufacturing philosophy that includes modern automation systems with a cretin level autonomy, flexible and effective data exchanges encoring the implementation of next generation production technologies, innovation in design, and more personal and more agile in production as well as customize products." (Oztemel and Gursev, 2020, p. 166).

In total, we labeled 15 documents on the I4.0 research stream. The authors employed methods such as literature review, case study, workshops, and interpretive structural modeling in their studies. Unlike the other streams, the papers on this category were published in diverse sources, which express multidisciplinary in the areas. It includes journals on industrial and organization management, applied science, strategy and logistics, information technology, and communication.

Considering the initial stage of researchers on this topic, the major of the studies explores the connection between I4.0 and CE concepts (e.g., Nobre and Tavares, 2017, 2020b, 2020a; Chauhan, Sharma and Singh, 2019; Rosa et al., 2020). Additionally, some studies debate technology employment to a specific process. For instance, the papers of Gu and Liu (2013) and Garrido-Hidalgo et al. (2019) discussed the IoT usage to a system and reverse supply chain. Other articles highlighted the I4.0 potential to maximize the remanufacturing sector (e.g., Yang et al., 2018; Kerin and Pham, 2019). Finally, other researchers focus on the metallurgy process (Reuter, 2016) and intelligent robotics technology applied in waste management (Sarc et al., 2019).

With respect to research gaps, most of the papers emphasize the need to test and validate concepts, frameworks, and models developed by the authors (Lopes de Sousa Jabbour et al., 2018; Chauhan, Sharma and Singh, 2019; Garrido-Hidalgo et al., 2019; Nobre and Tavares, 2020b). These findings reinforce the initial stage of knowledge in the area since many studies claimed practical applications and empirical evidence of I4.0 to CE (Lopes de Sousa Jabbour et al., 2018; Chauhan, Sharma and Singh, 2019; Rosa et al., 2020). Other critical research topics are DTs economic viability and the need for measures and indicators to analyze gains and circularity in organizations (Kerin and Pham, 2019; Nobre and Tavares, 2020b). Only the I4.0 research stream emphasized the lack of studies addressing required capabilities to a Smart CE (Lopes de Sousa Jabbour et al., 2018; Nobre and Tavares, 2020b). Besides, researches of emerging countries such as India and Brazil are the only ones insisting on the urgency of more studies focusing on multi-cultural challenges and barriers of employ DTs (Lopes de Sousa Jabbour et al., 2018; Cezarino et al., 2019; Rajput and Singh, 2019). These countries' reality is utterly distinct 
from European and North American nations, and possibly the phenomenon of I4.0 and CE behave differently compared to developed countries.

\subsection{Research Stream 2: Business}

The second research stream concentrates on the impact of digital transformation on businesses for creating new value offerings to clients, leveraged by DTs. In this group, scholars are interested in the transition of linear business models to smart circular business models.

Out of the 40 papers analyzed, 17 are part of the business research stream. The analytical methods applied are similar to the I4.0 research stream, including literature review, case studies, interviews with experts, workshops, and interpretive structural modeling. Nevertheless, unlike the first research stream, studies labeled as Business are less diverse in their publication source. Most of them are from Sustainability, Journal of Cleaner Production, Technological Forecasting and Social Change, and CIRP conference. All these sources are well-known in literature and hold a significant part of the bibliographic collection on the topic of interest.

Some studies employ the term digitalization as the principal focus in their analyses on the Business research stream. Digitalization is associated with the utilization of DTs to leverage a solution (product or/and service). According to Parida, Sjödin and Reim (2019, p. 6), digitalization definition is the "use of digital technologies to innovate a business model and provide new revenue streams and valueproducing opportunities in industrial ecosystems". Therefore, the papers aim to discuss how the DTs support the circular strategies and the transition to circular business models (CBM) (Pagoropoulos, Pigosso and McAloone, 2017; Planing, 2017; Okorie et al., 2018; Ingemarsdotter et al., 2019) and what are the main opportunities and challenges on digital transformation in a circular economic model (Antikainen, Uusitalo and Kivikytö-Reponen, 2018; Moreno et al., 2019).

A relevant factor to be mentioned on this stream is the focal point of Big Data (BDA) to activities management, decision-making, and sustainable business practices (Boone, Skipper and Hazen, 2017; Gupta et al., 2019). Also, the primary business model investigated is the product-service system (PSS). For instance, Bressanelli et al. (2018b) identified eight DTs' functionalities applied to usageoriented PSS. Zheng et al (2019), through a systematic literature review (SLR), recognized several challenges of Smart PSS implementation. Alcayaga, Wiener and Hansen (2019) integrated the CE, IoT, and PSS concept providing a framework of smart circular systems.

Moving from purpose to research gaps, the studies suggest that literature needs to advance on the frameworks, models, and concepts validation (Alcayaga, Wiener and Hansen, 2019; Jabbour et al., 2019). There is a lack of quantitative studies (Strandhagen et al., 2017) and papers assessing environmental impacts and rebound effects of DTs' usage (Moreno et al., 2019). Since most of the articles evaluated PSS, further research can focus on distinct business models and the design of CBM (Bressanelli et al., 2018a). Moreover, other DTs (beyond IoT and BDA) need to be explored (Bressanelli et al., 2018b). Future studies could concentrate on the consumers' acceptance of digital circular business (Planing, 2017) and data security and privacy concerns (Gupta et al., 2019).

\subsection{Research Stream 3: Sustainability}

The third identified research stream emphasizes sustainability questions, especially discussing (1) industrial symbiosis and (2) urban, industrial, and agricultural waste management. Out of the three research streams, Sustainability considered the biological cycle of CE, stressing the DTs' usage to the valorization of agricultural by-products and energy optimization. In total, eight documents were allocated in this category. The leading journals of the sustainability research stream are the Resource Conservation and Recycling and the Journal of Cleaner Production. The main methods used are literature review, case studies, and application of LCA.

The purposes of studies addressed how the DTs can maximize resource efficiency (Nižetić et al., 2019) and assist the LCA process (Zhang et al., 2020). They also focus on BDA employment to discover possibilities of industrial symbioses (Song et al., 2017) and support the agribusiness supply chain design (Belaud et al., 2019). Like the other streams, research on this category discussed DTs' barriers and opportunities, but focusing on waste management (Zhang et al., 2019).

Finally, the suggestions for future researches are similar to the other research streams. Authors reinforced (1) the need for validation of models and concepts developed (Esmaeilian et al., 2018; Kerdlap, Low and Ramakrishna, 2019; Zhang et al., 2020), (2) more empirical evidence regarding the benefits of Smart CE 
(Nižetić et al., 2019), (3) more debate on the barriers that should be overcome (Zhang et al., 2019) and (4) further studies to extend the scope of DTs application to reach circularity (Zhang et al., 2020).

\subsection{Implications to design research}

Product design has already been widely recognized as a key element in guiding the transition to the CE (den Hollander, Bakker and Hultink, 2017). However, the design goes beyond aspects associated with the product and expands to the development of new circular business models or even to the planning of smart sustainable cities. Our results suggest that the research streams may support the scope delimitation of design scholars. For example, research that focuses on new product development can use the Industry 4.0 research stream to understand how DTs apply or facilitate product improvement and upgrade.

In general, we observed that design applied to the micro-level (single company) (Ghisellini, Cialani and Ulgiati, 2016) was the most explored by the literature, especially regarding the Business research stream. For example, Ingemarsdotter et al. (2019) identified design evolution as an IoT capability that has the potential to influence different circular strategies, such as increasing efficiency and maximizing the useful life of products. This study is consistent with the findings of Bressanelli et al. (2018a). They identified eight functionalities of the IoT and BDA technologies, the first of which refers to improving the product design. Thus, companies can collect usage data and develop solutions that effectively address customer demands (Bressanelli et al., 2018a). However, both studies mentioned earlier demonstrated that this capability was more challenging to observe in practice.

Beyond IoT and BDA technologies, Blockchain also plays an essential role in transitioning to a CE. LCA based on Blockchain usage can guide decisions that affect the supply chain design (Zhang et al., 2020). Design is one of the CE principles demonstrating a greater propensity to obtain benefits of the DTs' employment (Nobre and Tavares, 2020b). For example, the design is addressed either to the development of new circular businesses (Rosa et al., 2020) to support components' design that facilitates recycling and remanufacturing processes (Nobre and Tavares, 2020b) or to design smart cities (Esmaeilian et al., 2018; Nobre and Tavares, 2020b). DTs to CE offer opportunities to further investigation in all lifecycle phases, distinct application levels (micro, meso, and macro), and different research streams.

In our analysed papers, some gaps regarding research design have been previously indicated. Zhang et al. (2020) emphasized the urgency of design products and services considering strategies to reduce endof-life waste management such as remanufacturing, reusing, and upgrading. Ingemarsdotter et al. (2019) defended that the possibility of acquiring data during product usage should not just be applied to improve product performance but should be seen as valuable insights that can be used in the next product design generation. Moreover, some challenging set of questions remain unexplored. (1) How should companies coordinate distinct stakeholders and ecosystem partners to design coherent circular solutions? Circular initiatives extend beyond the boundaries of a firm. The ecosystem perspective foments the development of circular initiatives, as it coordinates different parts towards a common goal. Design research can focus not only on a company but on the ecosystem as a whole. (2) How can design be applied to boost biological cycles such as cascade use initiatives? Within the context of design, it is common to find research aiming to develop proposals for the technical cycle of CE. Design research can focus on how to integrate both cycles and thus obtain more economical and environmental benefits. (3) How can design guide companies to consider the social pillar in their circular business models? Based on the pillars of sustainability, CE even though it can influence the social aspect, there are not many examples that explore this topic. Assessing the effects caused by circular initiatives, both the unexpected and the rebound effects, and their impacts on society are of great value for the development of theory. We expect that this study offers insights to advance research on sustainable and circular design.

\section{CONCLUSION}

We identified three research streams associating the CE and DTs. (1) The I4.0 research stream showed the studies focus on the importance and role of I4.0 to guide the transition to a CE. (2) The Business research stream clustered papers that discuss the impact of digital transformation in business, especially smart circular business models. (3) The Sustainability research stream stressed studies on sustainability issues such as industrial symbioses and waste management.

In a broader perspective, the studies analyzed aiming to develop and explore the association between DTs and CE. We observed focus on the economic and environmental aspects, which indicate that few 
studies mention the social aspect (e.g., employee generation and customer acceptance). The social pillar is not the main point on the research intersection between CE and DTs. This result demonstrates that studies have not been advancing to develop social elements. Additionally, in the papers addressing environmental aspects, we highlight the lack of studies correlating DTs' role to leverage the biological cycles such as agricultural applications to system regeneration.

In line with the intersection of the key concepts, we reinforce the authors' need to explore the relation between CE and DTs both on the empirical evidence and studies of multidisciplinary areas and multigeographics. The CE and DTs concepts required advancement in practical actions and joint research that advanced the transition to an CE understanding to develop and emergent countries.

The analyzed papers focus on actions to operation (middle-of-life) and end-of-life strategies such as implementing DTs on SCM and reverse logistics. However, in the initial stages of strategy development (the BoL phase) that affect the products 'and processes' life cycles, we point out that more initiatives aim to understand how DTs can minimize resources and raw material extraction to leverage CE are necessary. Studies should focus on design for sustainability that employs DTs since the conception of new business models to ensure circular and sustainable goals.

The study has some limitations. The first one is regarding our research string. We focus only on three DTs, which are stressed in literature as crucial DTs to perform the transition to a CE. They are IoT, Big Data, and Artificial Intelligence. Although this limitation, we included other keywords such as digital* that return papers with different applications and purposes. The second limitation refers to how the systematic literature review approach was conducted. A more significant number of experts could have participated in selecting and analyzing articles to increase the results' reliability and reduce the bias. Also, our study was limited to analyzing articles published only in journals and conferences even though we have used different databases. Documents published in other sources could provide insights and keyconcepts that may have been ignored in this study. Finally, a quantitative analysis of the selected papers, presenting the evolution of studies by research stream over the years, would be desirable.

\section{ACKNOWLEDGMENTS}

The author would like to thank the Higher Education Personnel Improvement Coordination (CAPES) Finance Code 001, Newton Mobility Grants 2019 (NMGIR1\191115), EPSRC Internet of Food Things Network Plus (EP/R045127/1), and the São Paulo Research Foundation (FAPESP) - under the process 2019/23655-9 - for supporting this research. The opinions, hypotheses, conclusions and recommendations expressed in this material are the responsibility of the authors and do not necessarily reflect the views of the funding bodies.

\section{REFERENCES}

Alcayaga, A., Wiener, M. and Hansen, E. G. (2019) 'Towards a framework of smart-circular systems: An integrative literature review', Journal of Cleaner Production. Elsevier Ltd, 221, pp. 622-634. https://dx.doi.org/10.1016/j.jclepro.2019.02.085.

Antikainen, M., Uusitalo, T. and Kivikytö-Reponen, P. (2018) 'Digitalisation as an Enabler of Circular Economy’, 10th CIRP Conference on Industrial Product-Service Systems. Elsevier B.V., 73, pp. 45-49. https://dx.doi.org/10.1016/j.procir.2018.04.027.

Belaud, J. P. et al. (2019) 'Big data for agri-food 4.0: Application to sustainability management for by-products supply chain', Computers in Industry. Elsevier B.V., 111, pp. 41-50. https://dx.doi.org/10.1016/j.compind.2019.06.006.

Bocken, N. M. P. et al. (2016) 'Product design and business model strategies for a circular economy', Journal of Industrial and Production Engineering. Taylor, 33(5), pp. 308-320. https://dx.doi.org/10.1080/21681015.2016.1172124.

Boone, C. A., Skipper, J. B. and Hazen, B. T. (2017) 'A framework for investigating the role of big data in service parts management', Journal of Cleaner Production. Elsevier Ltd, 153, pp. 687-691. https://dx.doi.org/10.1016/j.jclepro.2016.09.201.

Bressanelli, G. et al. (2018a) 'Exploring how usage-focused business models enable circular economy through digital technologies', Sustainability, 10(3). https://dx.doi.org/10.3390/su10030639.

Bressanelli, G. et al. (2018b) 'The role of digital technologies to overcome Circular Economy challenges in PSS Business Models: An exploratory case study', Procedia CIRP. Elsevier B.V., 73, pp. 216-221. https://dx.doi.org/10.1016/j.procir.2018.03.322.

Cezarino, L. O. et al. (2019) 'Diving into emerging economies bottleneck: Industry 4.0 and implications for circular economy’, Management Decision. Emerald Group Publishing Ltd. https://dx.doi.org/10.1108/MD-10-2018-1084.

Chauhan, C., Sharma, A. and Singh, A. (2019) 'A SAP-LAP linkages framework for integrating Industry 4.0 and circular economy’, Benchmarking. https://dx.doi.org/10.1108/BIJ-10-2018-0310. 
Ellen MacArthur Foundation (2015) Growth within: a circular economy vision for a competitive europe, Ellen MacArthur Foundation.

Ellen MacArthur Foundation (2019) 'Artificial Intelligence and the Circular Economy: Ai As a Tool To Accelerate', Report, p. 39. Available at: https://www.ellenmacarthurfoundation.org/publications/artificialintelligence-and-the-circular-economy.

Elo, S. and Kyngäs, H. (2008) 'The qualitative content analysis process', Journal of Advanced Nursing, 62(1), pp. 107-115. https://dx.doi.org/10.1111/j.1365-2648.2007.04569.x.

Esmaeilian, B. et al. (2018) 'The future of waste management in smart and sustainable cities: A review and concept paper', Waste Management. Elsevier Ltd, 81, pp. 177-195. https://dx.doi.org/10.1016/j.wasman.2018.09.047.

Garrido-Hidalgo, C. et al. (2019) 'An end-to-end Internet of Things solution for Reverse Supply Chain Management in Industry 4.0', Computers in Industry. Elsevier B.V., 112, p. 103127. https://dx.doi.org/10.1016/j.compind.2019.103127.

Geissdoerfer, M. et al. (2017) 'The Circular Economy - A new sustainability paradigm?', Journal of Cleaner Production. Elsevier Ltd, 143, pp. 757-768. https://dx.doi.org/10.1016/j.jclepro.2016.12.048.

Ghisellini, P., Cialani, C. and Ulgiati, S. (2016) 'A review on circular economy : the expected transition to a balanced interplay of environmental and economic systems', 114.

$\mathrm{Gu}, \mathrm{Y}$. and Liu, Q. (2013) 'Research on the application of the internet of things in reverse logistics information management', Journal of Industrial Engineering and Management, 6(4), pp. 963-973. https://dx.doi.org/10.3926/jiem.793.

Gupta, S. et al. (2019) 'Circular economy and big data analytics: A stakeholder perspective', Technological Forecasting and Social Change. Elsevier, 144(October 2017), pp. 466-474. https://dx.doi.org/10.1016/j.techfore.2018.06.030.

Guzzo, D. et al. (2019) 'Circular innovation framework: Verifying conceptual to practical decisions in sustainability-oriented product-service system cases’, Sustainability (Switzerland), 11(12). https://dx.doi.org/10.3390/su11123248.

den Hollander, M. C., Bakker, C. A. and Hultink, E. J. (2017) 'Product Design in a Circular Economy: Development of a Typology of Key Concepts and Terms', Journal of Industrial Ecology, 21(3), pp. 517525. https://dx.doi.org/10.1111/jiec.12610.

Ingemarsdotter, E. et al. (2019) 'Circular strategies enabled by the internet of things-a framework and analysis of current practice’, Sustainability (Switzerland), 11(20), p. 5689. https://dx.doi.org/10.3390/su11205689.

Jabbour, C. J. C. et al. (2019) 'Unlocking the circular economy through new business models based on largescale data: An integrative framework and research agenda', Technological Forecasting and Social Change. Elsevier, 144(June 2017), pp. 546-552. https://dx.doi.org/10.1016/j.techfore.2017.09.010.

Kerdlap, P., Low, J. S. C. and Ramakrishna, S. (2019) 'Zero waste manufacturing: A framework and review of technology, research, and implementation barriers for enabling a circular economy transition in Singapore', Resources, Conservation and Recycling. Elsevier, 151(August), p. 104438. https://dx.doi.org/10.1016/j.resconrec.2019.104438.

Kerin, M. and Pham, D. T. (2019) 'A review of emerging industry 4.0 technologies in remanufacturing', Journal of Cleaner Production. Elsevier Ltd, 237, p. 117805. https://dx.doi.org/10.1016/j.jclepro.2019.117805.

Kristoffersen, E. et al. (2020) 'The smart circular economy: A digital-enabled circular strategies framework for manufacturing companies', Journal of Business Research. Elsevier, 120(July), pp. 241-261. https://dx.doi.org/10.1016/j.jbusres.2020.07.044.

Lopes de Sousa Jabbour, A. B., et al. (2018) 'Industry 4.0 and the circular economy: a proposed research agenda and original roadmap for sustainable operations', Annals of Operations Research. Springer US, 270(1-2), pp. 273-286. https://dx.doi.org/10.1007/s10479-018-2772-8.

Moreno, M. et al. (2019) 'Opportunities for redistributed manufacturing and digital intelligence as enablers of a circular economy’, International Journal of Sustainable Engineering. Taylor \& Francis, 12(2), pp. 77-94. https://dx.doi.org/10.1080/19397038.2018.1508316.

Nasiri, M., Tura, N. and Ojanen, V. (2017) 'Developing disruptive innovations for sustainability: A review on Impact of Internet of Things (IOT)', PICMET 2017 - Portland International Conference on Management of Engineering and Technology: Technology Management for the Interconnected World, Proceedings, 2017Janua(April 2019), pp. 1-10. https://dx.doi.org/10.23919/PICMET.2017.8125369.

Nižetić, S. et al. (2019) 'Smart technologies for promotion of energy efficiency, utilization of sustainable resources and waste management', Journal of Cleaner Production, 231, pp. 565-591. https://dx.doi.org/10.1016/j.jclepro.2019.04.397.

Nobre, G. C. and Tavares, E. (2017) 'Scientific literature analysis on big data and internet of things applications on circular economy: a bibliometric study’, Scientometrics. Springer Netherlands, 111(1), pp. 463-492. https://dx.doi.org/10.1007/s11192-017-2281-6.

Nobre, G. C. and Tavares, E. (2020a) 'Assessing the role of big data and the internet of things on the transition to circular economy: Part I An extension of the ReSOLVE framework proposal through a literature review', Johnson Matthey Technology Review, 64(1), pp. 19-31. https://dx.doi.org/10.1595/205651319x15643932870488. 
Nobre, G. C. and Tavares, E. (2020b) 'Assessing the role of big data and the internet of things on the transition to circular economy: Part II An extension of the ReSOLVE framework proposal through a literature review', Johnson Matthey Technology Review, 64(1), pp. 32-41. https://dx.doi.org/10.1595/205651319x15650189172931.

Okorie, O. et al. (2018) 'Digitisation and the circular economy: A review of current research and future trends', Energies, 11(11), pp. 1-31. https://dx.doi.org/10.3390/en11113009.

Oztemel, E. and Gursev, S. (2020) 'Literature review of Industry 4.0 and related technologies', Journal of Intelligent Manufacturing. Springer US, 31(1), pp. 127-182. https://dx.doi.org/10.1007/s10845-018-1433-8.

Pagoropoulos, A., Pigosso, D. C. A. and McAloone, T. C. (2017) 'The Emergent Role of Digital Technologies in the Circular Economy: A Review', The 9th CIRP IPSS Conference. The Author(s), 64, pp. 19-24. https://dx.doi.org/10.1016/j.procir.2017.02.047.

Parida, V., Sjödin, D. and Reim, W. (2019) 'Reviewing literature on digitalization, business model innovation, and sustainable industry: Past achievements and future promises', Sustainability (Switzerland), 11(2). https://dx.doi.org/10.3390/su11020391.

Paul, J. and Criado, A. R. (2020) 'The art of writing literature review: What do we know and what do we need to know?', International Business Review. Elsevier, 29(4), p. 101717. https://dx.doi.org/10.1016/j.ibusrev.2020.101717.

Pham, T. T. et al. (2019) 'Industry 4.0 to accelerate the circular economy: A case study of electric scooter sharing', Sustainability (Switzerland), 11(23), pp. 1-16. https://dx.doi.org/10.3390/su11236661.

Pieroni, M. P. P., McAloone, T. C. and Pigosso, D. C. A. (2019) 'Business model innovation for circular economy and sustainability: A review of approaches', Journal of Cleaner Production. Elsevier Ltd, 215, pp. 198-216. https://dx.doi.org/10.1016/j.jclepro.2019.01.036.

Planing, P. (2017) 'Will digital boost circular ? Evaluating the impact of the digital transformation on the shift towards a circular economy', International Journal of Management Cases, (January), pp. 22-31.

Porter, M. E. and Heppelmann, J. E. (2014) 'How Smart, Connected Products Are Transforming Competition', Harvard Business Review, 92(11), p. 64.

Rajput, S. and Singh, S. P. (2019) 'Industry 4.0 - challenges to implement circular economy', Benchmarking. https://dx.doi.org/10.1108/BIJ-12-2018-0430.

Reuter, M. A. (2016) 'Digitalizing the Circular Economy: Circular Economy Engineering Defined by the Metallurgical Internet of Things', Metallurgical and Materials Transactions B: Process Metallurgy and Materials Processing Science. Springer US, 47(6), pp. 3194-3220. https://dx.doi.org/10.1007/s11663-016-0735-5.

Rosa, P. et al. (2020) 'Assessing relations between Circular Economy and Industry 4.0: a systematic literature review', International Journal of Production Research. Taylor \& Francis, 58(6), pp. 1662-1687. doi: https://doi.org/10.1080/00207543.2019.1680896.

Sarc, R. et al. (2019) 'Digitalisation and intelligent robotics in value chain of circular economy oriented waste management - A review', Waste Management. Elsevier Ltd, 95, pp. 476-492. https://dx.doi.org/10.1016/j.wasman.2019.06.035.

Sauvé, S., Bernard, S. and Sloan, P. (2016) 'Environmental sciences, sustainable development and circular economy: Alternative concepts for trans-disciplinary research', Environmental Development. Elsevier, 17, pp. 48-56. https://dx.doi.org/10.1016/j.envdev.2015.09.002.

Song, B. et al. (2017) 'Industrial Symbiosis: Exploring Big-data Approach for Waste Stream Discovery', Procedia CIRP, 61, pp. 353-358. https://dx.doi.org/10.1016/j.procir.2016.11.245.

Strandhagen, J. O. et al. (2017) 'Logistics 4.0 and emerging sustainable business models', Advances in Manufacturing. Shanghai University, 5(4), pp. 359-369. https://dx.doi.org/10.1007/s40436-017-0198-1.

Tranfield, D., Denyer, D. and Smart, P. (2003) 'Towards a methodology for developing evidence-informed management knowledge by means of systematic review', British Journal of Management, 14(2), pp. 207222. https://dx.doi.org/10.2307/249689.

Webster, J. and Watson, R. T. (2002) 'Analyzing the past to prepare for the future: Writing a literature review', MIS Quarterly, pp. xiii-xxiii. https://dx.doi.org/10.1016/j.freeradbiomed.2005.02.032.

Yang, S. et al. (2018) 'Opportunities for industry 4.0 to support remanufacturing', Applied Sciences (Switzerland), 8(7). https://dx.doi.org/10.3390/app8071177.

Zhang, A. et al. (2019) 'Barriers to smart waste management for a circular economy in China', Journal of Cleaner Production. Elsevier Ltd, 240, p. 118198. https://dx.doi.org/10.1016/j.jclepro.2019.118198.

Zhang, A. et al. (2020) 'Blockchain-based life cycle assessment: An implementation framework and system architecture', Resources, Conservation and Recycling. Elsevier, 152(August 2019), p. 104512. https://dx.doi.org/10.1016/j.resconrec.2019.104512.

Zheng, P. et al. (2019) 'A survey of smart product-service systems: Key aspects, challenges and future perspectives', Advanced Engineering Informatics. Elsevier, 42(August), p. 100973. https://dx.doi.org/10.1016/j.aei.2019.100973. 